\title{
The efficiency of urban combined sewer systems during wet weather
}

\author{
Ewa Burszta-Adamiak ${ }^{1, *}$, Justyna Stańczyk ${ }^{1}$, Janusz Łomotowski ${ }^{1}$, and Tomasz \\ Konieczny ${ }^{2}$ \\ ${ }^{1}$ Wroclaw University of Environmental Sciences, Institute of Environmental Engineering, pl. \\ Grunwaldzki 24, 50-363 Wroclaw, Poland \\ ${ }^{2}$ The New Technologies Centre, Municipal Water and Sewage Company S.A. in Wroclaw (MPWiK), \\ ul. Na Grobli 14/16, 50-421 Wrocław, Poland
}

\begin{abstract}
The intensive development of urban areas results in the sealing of increasingly large areas. In such conditions the existing sewer systems are quite often unable to simultaneously collect sewage along with the additional volume of rainwater. These systems require control of the hydraulic parameters in order to recognize the hydraulic conditions that occur in different operational states. Nowadays, such control may be exercised through the use of models that are capable of prediction as a result of the process of learning from a database of historical events. The study presents the possibilities of using Artificial Neural Networks (ANNs) for the analyses of the time series of waste-water depth and flows in a combined sewer system. The measurement campaign organized in Wrocław (Poland) enabled obtaining data on the hydraulic parameters of the flow of sewage in the sewer systems, and rainfall of various characteristics. The test results demonstrate that algorithms of the MLP (Multi-Layered Perceptron) Artificial Neural Network may be implemented to predict the flow rate in the system. The method presented in the paper may be applied to the daily operation of sewer systems to predict transient flows. The obtained results demonstrate a good and very good accuracy of prediction model.
\end{abstract}

\section{Introduction}

Management of urban combined sewer systems, whose task is to collect and transport both municipal sewage and rainwater, is becoming a challenge for the waterworks and sewage sector. Networks located in sealed catchments of urban areas are exposed to significant hydraulic loads, resulting from a large volume of rainwater runoff flowing into the sewer systems during rainfall. In such conditions, so-called flash floods are becoming increasingly frequent. They result in outflows from the sewer system and flooding, contributing to numerous social, economic and property losses [1]. Observation of these types of phenomena and the increasing frequency of their occurrence in recent years force us to continuously improve the methods of predicting changes in the hydraulic parameters in

\footnotetext{
*Corresponding author: ewa.burszta-adamiak@upwr.edu.pl
} 
sewage systems. In such a situation, a method based on a traditional approach and the use of nomograms or hydraulic efficiency diagrams of sewers (so called efficiency curves) to determine the rate of flow and sewage depth in pipes is insufficient. The non-linear dependence between the inflow and outflow in the sewer also makes it more difficult to formulate a description of the phenomenon with the use of mathematical models based on fundamental laws of physics [2]. Even if such mathematical model exists, it is not always possible to draw conclusions on how to manage the facility to achieve the desired objective. In reality, the nature of flows in the system is non-determined and their changeability depends on the uneven discharge of municipal sewage and rainwater runoff. As far as the first ones are concerned, the dynamics of flow changes is relatively low. The highest differences in the flow of sewage and the depth of flow in sewers are noted during rainy weather, because it is the dynamics of rainfall and the resulting surface runoff with the transformation of the outflow wave in the sewer pipes that determine the transient runoff in sewer systems [3].This issue becomes even more complex if we consider the changeability of flows in sewers of different cross-sections and during rainfall of various characteristics, i.e. rain depth, duration and intensity. In such situation, although it is necessary to maintain continuous control of the hydraulic parameters in sewers, it is very time-consuming and requires high expenditure. There is a need to search for models that would predict the values of time series in the future based on the knowledge of historical data.

Artificial Neural Networks (ANNs) are a tool that makes this possible. They enable the modelling of complex dependencies between inputs and outputs [4]. Known examples of using Artificial Neural Networks for predicting phenomena refer to these areas that may be characterized by a numerous time series. So far, ANNs have been used, among others, in predicting hydrological [5,6], meteorological [7-9] and economic phenomena [10,11] and in solving various groundwater problems [12]. As far as predicting the operation of sewer networks in terms of the rainfall-discharge ratio is concerned, most publications are devoted to the presentation of the results of research on the application of Artificial Neural Networks for predicting the risk of Combined Sewer Overflow (CSO) and floods [1,13-14]. Only a few publications discuss the use of ANNs for simulating the amount of pollutants transported in sewer systems [2]. However, the potential for application of Artificial Neural Networks is much larger. The aim of this paper was to assess the possibility to apply Artificial Neural Networks for the analysis of time series of depth of flow and flow in the combined sewer network of a circular and horseshoe-shaped cross-section during rainfall events of various characteristics. This constituted the basis for determining the usability of MLP (Multi-Layer Perception) type networks for predicting the flow rate of wastewater in a sewer system based data concerning wastewater depth in sewers, obtained from sewer monitoring conducted by the Municipal Water and Sewage Company S.A. in Wroclaw (Poland).

\section{Study area and data pre-processing}

In order to assess the possibility of predicting the hydraulic parameters that exist inside a combined sewer system, five rainfall events of various natures that occurred in the period from June to September 2012 were selected. These events differed in terms of rainfall duration, intensity and rainfall depth. According to the characteristics of rainfall provided in the Chomicz scale they fell into the range of torrential rainfall and heavy rainfall with a short and long duration. Detailed information about these rainfall events is provided in Table 1. In order to verify the hydraulic conditions of flow in sewers specifically for municipal sewage, the analysis also included two periods of dry weather. The sewers whose hydraulic parameters constituted the scope of research are located in the north-western part of the city of Wrocław. The first of them has a circular cross-section of a nominal diameter 
DN1800. The dimensions of the second, horseshoe-shaped sewer are $3500 \times 2800 \mathrm{~mm}$. The measurement interval was 5 minutes for hydraulic parameters existing in the sewer and 1 minute for rainfall recorded with use of a distrometer.

The implementation of calculation procedures in the form of Artificial Neural Networks was conducted with the use of Statistica 13.1 software. Overall, a total of seven models were created to predict the rate of wastewater flow for each of the sewers during individual rainfall events and dry weather periods. The time series of the flow rate in the sewer, being the values subject to prediction, were estimated based on the input data constituting the depth of flow for sewers.

The flow rate was predicted with the use of MLP networks with 6 input neurons, a changeable number of neurons in one perceptron layer and one output neuron. The input variables were the depths of wastewater in sewers 30 minutes before the predicted values constituting the output neuron (measurements 5, 10, 15, 20, 25 and $30 \mathrm{~min}$. before the predicted value of flow rate). The Authors chose a random data sampling method. The data were divided into a train dataset of $70 \%$, test dataset of $15 \%$ and validation dataset of $15 \%$. The selected type of ANN was the one-directional, multi-layered MLP (Multi-Layered Perceptron) network. The Back Propagation network learning technique was used along with the BFGS (Broyden-Fletcher-Goldfarb-Shanno) algorithm.

The first stage of research consisted in checking whether there were any correlations between the parameters of specific rainfall events (or the lack thereof) and the operational status of combined sewer systems. The correlations between the rainfall depth, its average and maximum intensity and duration and the average flow rate inside the sewer were analyzed. In the second stage of the analyses, the time series of flow rate and depth of wastewater in the sewer (along with the assumed series of predictions) were implemented, respectively, as input and output data of the model created with the use of Artificial Neural Networks. The final step of the analyses conducted with the use of Artificial Neural Networks consisted in creating matrices of the correlation between the prediction accuracy provided by different models and the parameters of the selected rainfall events. The main aim of this stage of research was to find links between the correlation coefficient of the test dataset and the size of prediction errors and the nature of the selected rainfall events.

\section{Results and discussion}

The created correlation matrices constituted a basis for demonstrating a statistically significant correlation between the maximum and average flow rate in sewers and the rain depth. A lower, but still significant (0.756) correlation coefficient $\mathrm{R}$ was obtained for the correlation between average wastewater flow rate in sewer pipes and the duration of rainfall. On the other hand, the authors did not find a significant correlation between the average and maximum rainfall intensity and the flow rate in sewer pipes. Due to the fact that the dimensions of the analysed sewers are large, rain depth and duration have a stronger influence on the obtained flow rates in sewer pipes than rainfall intensity. However, the authors bear in mind that the available time series are too short to unambiguously underestimate the role of the influence of rainfall intensity on the wastewater flow rate in sewers. In Wrocław, an increasing tendency in rainfall intensity has been noted. This needs to be taken into account when designing drainage systems [15]. As a result, this issue will require a more in-depth analysis on an increased number of rainfall events in the future.

The results of the process of predicting the flow rate in sewer pipes based on the depth of wastewater level in the sewer are presented in Table 1. 


\begin{tabular}{|c|c|c|c|c|c|c|c|c|c|c|c|c|c|c|c|c|}
\hline 望 $0^{\circ}$ & & $\begin{array}{l}n \\
n \\
n \\
1\end{array}$ & $\stackrel{2}{\stackrel{2}{-1}}$ & $\begin{array}{l}\vec{n} \\
0 \\
1\end{array}$ & $\begin{array}{l}\hat{n} \\
0 \\
0\end{array}$ & $\underset{7}{8}$ & $\begin{array}{l}\hat{6} \\
0 \\
1\end{array}$ & $\begin{array}{l}8 \\
8 \\
0\end{array}$ & & $\begin{array}{l}\stackrel{2}{\circ} \\
\text { in }\end{array}$ & $\stackrel{\infty}{\infty}$ & $\begin{array}{l}\hat{\sigma} \\
+\end{array}$ & $\begin{array}{l}n \\
\hat{\sigma}\end{array}$ & $\hat{o}$ & 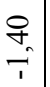 & $\begin{array}{l}\dot{H} \\
\dot{m} \\
\dot{\varphi}\end{array}$ \\
\hline 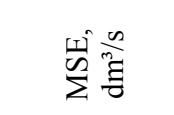 & & $\begin{array}{l}\infty \\
\stackrel{\infty}{\Xi} \\
\vec{\Xi}\end{array}$ & 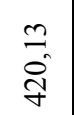 & 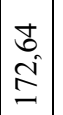 & $\begin{array}{l}\stackrel{0}{0} \\
\stackrel{-}{0} \\
\end{array}$ & 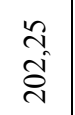 & $\begin{array}{l}\overrightarrow{0} \\
0 \\
\bar{\sigma}\end{array}$ & $\begin{array}{l}\mathcal{Y} \\
\text { fo } \\
\text { f }\end{array}$ & & $\begin{array}{l}\text { oे } \\
\text { రิ } \\
\infty\end{array}$ & $\frac{i}{m}$ & 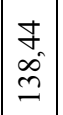 & $\begin{array}{l}n \\
i n \\
i n\end{array}$ & $\begin{array}{c}n \\
n \\
n \\
n \\
n\end{array}$ & $\begin{array}{l}\tilde{N} \\
\text { mे }\end{array}$ & $\begin{array}{l}\vec{J} \\
r\end{array}$ \\
\hline 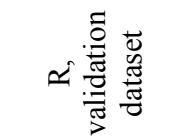 & & $\begin{array}{l}n \\
\hat{\sigma} \\
0\end{array}$ & 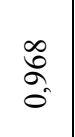 & $\begin{array}{l}\check{\alpha} \\
\sigma \\
\sigma\end{array}$ & $\begin{array}{l}2 \\
\infty \\
2 \\
0\end{array}$ & $\begin{array}{l}\circ \\
\text { ลे } \\
0\end{array}$ & 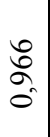 & $\begin{array}{l}\text { ra } \\
\hat{\sigma} \\
0\end{array}$ & & 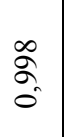 & $\begin{array}{l}\text { \&ू } \\
\text { o. }\end{array}$ & $\left|\begin{array}{l}2 \\
\delta \\
0 \\
0\end{array}\right|$ & $\mid \begin{array}{l}n \\
\hat{\alpha} \\
\sigma\end{array}$ & $\begin{array}{l}2 \\
\stackrel{\circ}{0}\end{array}$ & $\begin{array}{l}\text { : } \\
\text { م. } \\
0\end{array}$ & $\stackrel{n}{\hat{\sigma}}$ \\
\hline 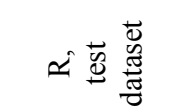 & & $\begin{array}{l}\infty \\
\infty \\
0 \\
0\end{array}$ & $\begin{array}{l}\infty \\
\infty \\
0 \\
0\end{array}$ & $\begin{array}{l}\hat{\sigma} \\
\hat{\sigma}\end{array}$ & $\begin{array}{l}\infty \\
\infty \\
0 \\
0\end{array}$ & $\hat{\sigma}$ & $\begin{array}{l}n \\
\hat{\sigma} \\
0\end{array}$ & $\hat{\sigma}$ & & $\stackrel{\infty}{\sigma}$ & $\begin{array}{l}0 \\
2 \\
0 \\
0\end{array}$ & $\begin{array}{l}\hat{\alpha} \\
\hat{\sigma}\end{array}$ & $\begin{array}{l}\circ \\
\text { ळ. } \\
0\end{array}$ & ڤ̆ & $\begin{array}{l}\infty \\
0 \\
\vdots \\
0\end{array}$ & 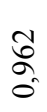 \\
\hline ح & & $\begin{array}{l}\infty \\
\hat{\sigma} \\
0\end{array}$ & 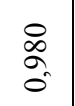 & $\begin{array}{l}\hat{\alpha} \\
\hat{\sigma}\end{array}$ & $\begin{array}{l}n \\
\infty \\
0 \\
0\end{array}$ & $\begin{array}{l}\infty \\
\sigma \\
\sigma\end{array}$ & $\begin{array}{l}\frac{n}{5} \\
\hat{\sigma}\end{array}$ & $\mid \begin{array}{l}\infty \\
\infty \\
0 \\
0\end{array}$ & & ஃ̆ & 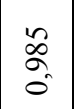 & $\left|\begin{array}{l}\infty \\
2 \\
\sigma \\
0\end{array}\right|$ & $\mid$ & $\begin{array}{l}\text { ूे } \\
\text { ठे }\end{array}$ & $\begin{array}{l}\stackrel{2}{a} \\
\hat{\sigma}\end{array}$ & $\begin{array}{l}\hat{0} \\
\circ \\
0\end{array}$ \\
\hline 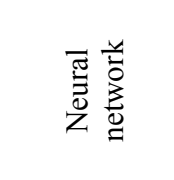 & $\frac{\stackrel{.}{2}}{\stackrel{0}{0}}$ & $\begin{array}{l}\vec{a} \\
\hat{b} \\
a \\
\vec{z}\end{array}$ & $\begin{array}{l}\vec{a} \\
\hat{b} \\
a_{1} \\
\dot{z}\end{array}$ & 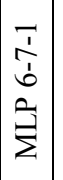 & 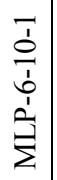 & $\begin{array}{l}7 \\
1 \\
b \\
0 \\
\dot{3}\end{array}$ & $\begin{array}{l}\overrightarrow{1} \\
b \\
b \\
o \\
\vec{z}\end{array}$ & $\begin{array}{l}7 \\
1 \\
b \\
0 \\
\vdots \\
\Sigma\end{array}$ & 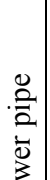 & $\begin{array}{l}\overline{1} \\
\hat{b} \\
a_{j} \\
\dot{z}\end{array}$ & $\begin{array}{l}\overline{1} \\
b \\
b \\
0 \\
\dot{b}\end{array}$ & $\left|\begin{array}{l}\vec{j} \\
0 \\
b \\
b \\
\vdots \\
\dot{z}\end{array}\right|$ & $\begin{array}{l}7 \\
\frac{1}{1} \\
b \\
2 \\
\vec{z} \\
\dot{2}\end{array}$ & $\begin{array}{l}\overline{1} \\
0 \\
b \\
0 \\
0 \\
\end{array}$ & $\begin{array}{l}\vec{j} \\
\hat{b} \\
\stackrel{2}{\xi} \\
\vec{\Sigma}\end{array}$ & $\begin{array}{l}\vec{b} \\
\frac{1}{b} \\
0 \\
\dot{2}\end{array}$ \\
\hline 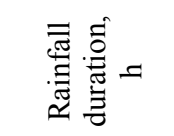 & 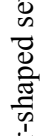 & 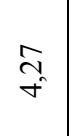 & $\stackrel{\infty}{=}$ & $\frac{2}{a}$ & $\begin{array}{l}\tilde{\hat{n}} \\
\tilde{\sim}\end{array}$ & $\begin{array}{l}\text { in } \\
i n\end{array}$ & , & ' & 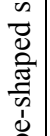 & $\begin{array}{l}\hat{N} \\
\stackrel{+}{*}\end{array}$ & $\stackrel{\infty}{=}$ & $\begin{array}{l}\stackrel{2}{2} \\
a\end{array}$ & $\begin{array}{l}\tilde{z} \\
\tilde{z}\end{array}$ & $\begin{array}{l}\vec{n} \\
i\end{array}$ & I & , \\
\hline 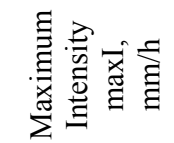 & 氞 & $\begin{array}{l}\stackrel{n}{6} \\
\frac{6}{6}\end{array}$ & $\begin{array}{l}\infty \\
\infty \\
\infty\end{array}$ & $\begin{array}{l}n \\
0 \\
q \\
q\end{array}$ & \begin{tabular}{l}
$i$ \\
$n$ \\
\multirow{f}{f}{}
\end{tabular} & 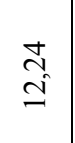 & ' & ' & 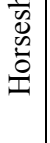 & $\frac{n}{6}$ & $\begin{array}{l}\infty \\
\infty \\
\infty\end{array}$ & $\left|\begin{array}{l}m \\
0 \\
\dot{q}\end{array}\right|$ & $\left|\begin{array}{l}i \\
n \\
f \\
f\end{array}\right|$ & $\begin{array}{l}\stackrel{ \pm}{\sim} \\
\text { I }\end{array}$ & I & ' \\
\hline 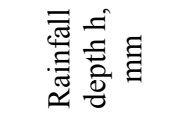 & & $\begin{array}{l}8 \\
i n \\
i n\end{array}$ & $\begin{array}{l}\circ \\
\forall\end{array}$ & $\begin{array}{l}\bar{\sigma} \\
\tilde{\sigma}\end{array}$ & $\begin{array}{c}\tilde{n} \\
\infty \\
n \\
n\end{array}$ & $\frac{ \pm}{6}$ & , & ' & & $\begin{array}{l}8 \\
i \\
m\end{array}$ & $\stackrel{\circ}{\stackrel{0}{f}}$ & $\begin{array}{l}\bar{\sigma} \\
\tilde{\sigma}\end{array}$ & $\begin{array}{c}n \\
n \\
\infty \\
n\end{array} \mid$ & $\frac{ \pm}{6}$ & I & ' \\
\hline 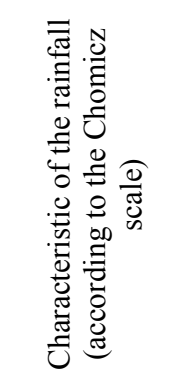 & & 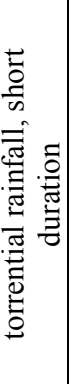 & 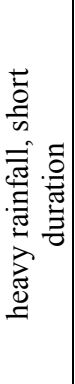 & 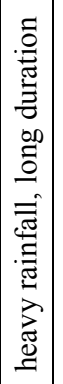 & 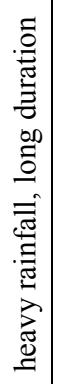 & 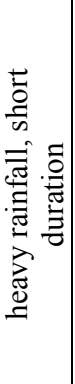 & 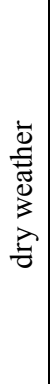 & 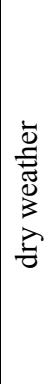 & & 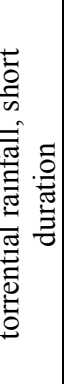 & 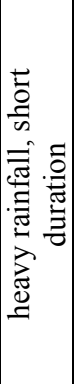 & 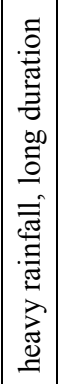 & 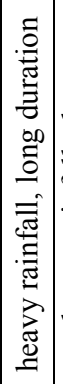 & 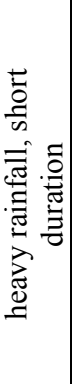 & 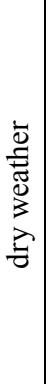 & 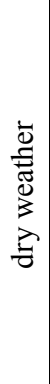 \\
\hline$\stackrel{\mathscr{\tilde { N }}}{0}$ & & 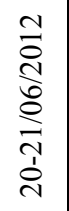 & 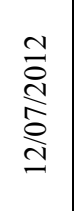 & 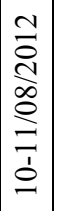 & 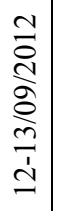 & $\begin{array}{l}\frac{1}{\circ} \\
\frac{N}{o} \\
\stackrel{o}{a}\end{array}$ & $\begin{array}{l}\frac{1}{2} \\
\stackrel{2}{2} \\
\frac{2}{2} \\
\end{array}$ & $\frac{\text { a }}{\stackrel{N}{0}}$ & & 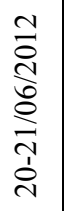 & 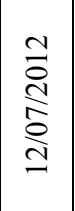 & 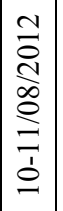 & 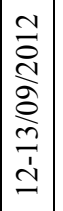 & 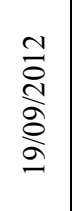 & 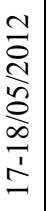 & 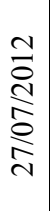 \\
\hline
\end{tabular}


The basic quality parameters of specific models of the analysed events for two selected cross-sections of pipes were also considered. In order to verify the accuracy of the obtained predictions, the correlation coefficients of the train, test and validation datasets were used, together with Mean Squared Error (MSE) and Mean Percentage Error (MPE). For all the rainfall events in the MLP network structure there were six neurons in the input layer and one neuron in the output layer. The number of neurons in the hidden layer is different, depending on which network achieved the best prediction accuracy. For torrential rainfall, both in circular and horseshoe-shaped sewers the hidden layer contained nine neurons, while in the remaining cases this number fluctuated from 3 to 10 neurons. The obtained coefficients of tests for all models showed nearly complete correlation between the observed and predicted parameters of wastewater flow rate in the sewer. However, this is not the ultimate factor determining the model accuracy. The Mean Squared Error demonstrates the difference in $\mathrm{dm}^{3 /} \mathrm{s}$ between the estimated values and the estimator. It is noticeable that the highest differences occur for torrential rainfall in both cases of the analysed pipe cross-sections. This is mainly due to the disturbances in the flow rate/water depth ratio that results from the occurrence of turbulent flow inside the pipe and, quite often, the fact that the whole capacity of the pipe was occupied by rainwater, which eventually spilled over through manholes to the surface. The event of June 20-21 2012 is characterised not only by significant rain depth $(35 \mathrm{~mm})$ but also by a high maximum intensity $(161.50 \mathrm{~mm} / \mathrm{h})$. Owing to this, it should be the subject of particular attention and the authors' plan to focus on it in future publications. MPE errors in most cases point to the underestimation of the selected models. According to the criteria adopted, among others, in research by Rogalska, Hajducki [16] the accuracy of predictions can be considered as accurate and good. Only the prediction for the torrential rain of June 20-21 should again be considered as not very accurate.

Figure 1 present example of hydrographs of observed and predicted flow rates along with rainfall hyetograph for the circular shaped sewer pipe. For the circular sewer pipe, the rainfall event of 10-11/08/2012 was selected, i.e. a heavy rainfall with a long duration. A runoff delay of approx. 300 minutes between the highest rainfall depth and the maximum flow rate of wastewater in the sewer was noted. At the points of the highest flow rates $\left(983 \mathrm{dm}^{3} / \mathrm{s}\right.$ and $\left.861 \mathrm{dm}^{3} / \mathrm{s}\right)$ the model is slightly underestimated.

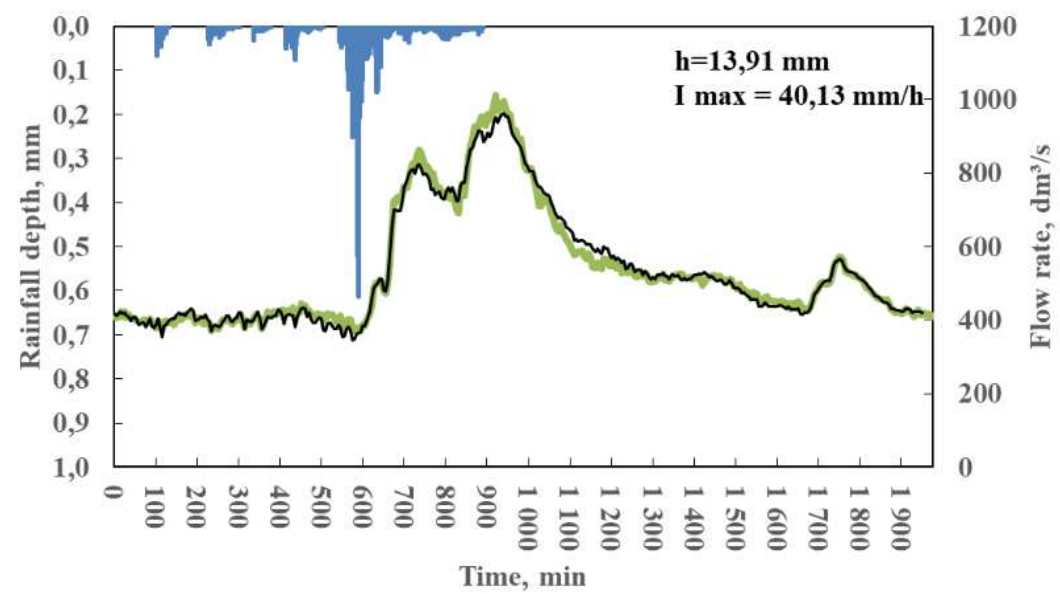

Rainfall - Observed flow rate - Predicted flow rate

Fig. 1. Rainfall hyetograph and flow rate hydrographs for a selected day (10-11/08/2012) for a circular-shaped sewer pipe. 
Considering the differences between the rainfall events, scatter plots and predicted flow rate values were created for selected rainfall events. Figure 2 shows as an example the distribution of values of these parameters for the circular sewer pipe. For the circular sewer pipe, during torrential and heavy rain with a long duration the best adjustment of the model is noted for flow rates that do not exceed $600 \mathrm{dm}^{3 /} \mathrm{s}$. For higher values, the prediction is less precise. During heavy rain with a short duration, the scatter around simple regression is negligible. For dry weather period, when the flow rate is affected only by the inflow of municipal sewage, the most accurate adjustment of the estimated values to the estimator is observed for the flow rate range $200-300 \mathrm{dm}^{3 /}$. Lower flow rate values were obtained during the night, when minimum night water demand is noted, resulting in Minimum Night Flow (MNF), which is also reflected in the sewer system.

a)

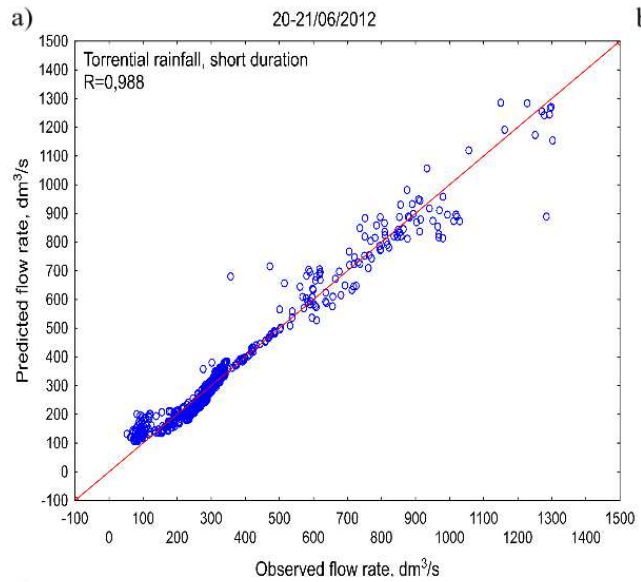

c)

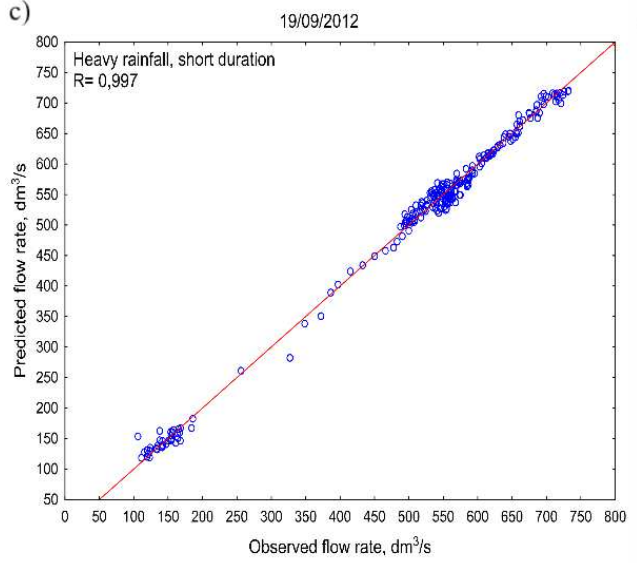

b)

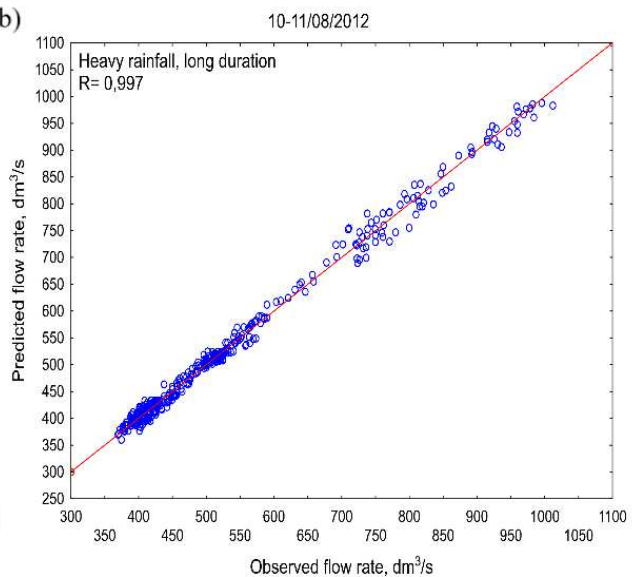

d)

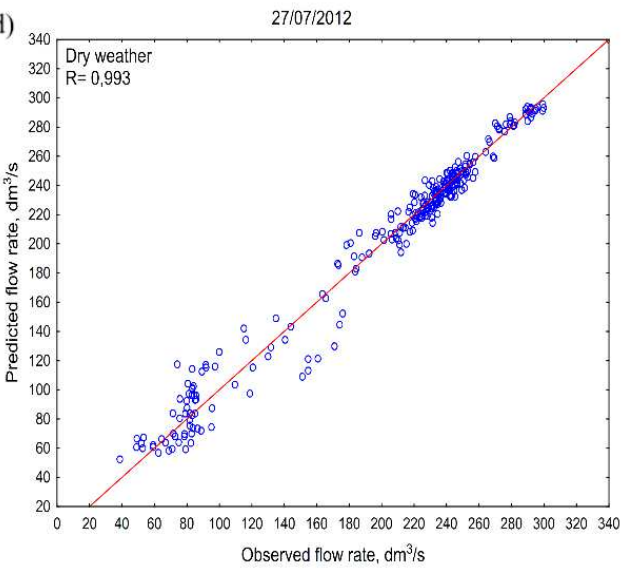

Fig. 2. Scatter plot for selected type of rainfall and dry weather for circular-shaped sewer pipe.

For the horseshoe-shaped sewer, the lowest scatter of points between the estimator and the estimated value is noticeable for heavy rainfall with a long duration. For torrential rain events, the best match was obtained for flow rates not exceeding $250 \mathrm{dm}^{3} / \mathrm{s}$. The dry weather period is characterized by the highest deviation from simple regression. This state should be confronted with the random nature of water consumption by users of the water supply network. However, for both the selected combined sewer pipes the scatter points lie along simple regression with small deviations, which finally results in a good and very good prediction accuracy. 
The matrices of correlation between the prediction accuracy of individual models and the parameters of the selected rainfall events that were developed in order to find links between the correlation coefficient of the test dataset and the size of prediction errors and the nature of the selected rainfall events are presented in Table 2. A statistically significant correlation was obtained between the rain depth and its maximum intensity and the Mean Squared Error (MSE). It was noted that the MSE error increases with the increase in rainfall depth. The value of the MPE error is also considerably affected by maximum rainfall intensity, although a negative correlation is noted here, i.e. the higher the intensity, the lower the MPE value.

Table 2. List of correlation coefficient (for $p<0.05$ ) of the influence of rainfall parameters on the errors of the neural network analysis.

\begin{tabular}{|c|c|c|c|c|c|c|}
\hline Parameter & $\begin{array}{c}\text { Rainfall } \\
\text { depth } \mathrm{h}, \\
\mathrm{mm}\end{array}$ & $\begin{array}{c}\text { Rainfall } \\
\text { maximum } \\
\text { intensity } \\
\text { Imax, } \mathrm{mm} / \mathrm{h}\end{array}$ & $\begin{array}{c}\text { Rainfall } \\
\text { duration } \mathrm{t}, \\
\mathrm{min}\end{array}$ & $\begin{array}{c}\text { Correlation } \\
\text { coefficient R, } \\
\text { test dataset }\end{array}$ & $\begin{array}{c}\text { MSE, } \\
\mathrm{dm}^{3} / \mathrm{s}\end{array}$ & $\begin{array}{c}\text { MPE, } \\
\%\end{array}$ \\
\hline $\begin{array}{c}\text { Rainfall depth } \\
\text { h, mm }\end{array}$ & 1,000 & 0,581 & 0,751 & 0,048 & $\mathbf{0 , 9 0 1}$ & $-0,326$ \\
\hline $\begin{array}{c}\text { Rainfall } \\
\text { maximum } \\
\text { intensity } \\
\text { Imax, mm/h }\end{array}$ & 0,581 & 1,000 & 0,015 & $-0,034$ & $\mathbf{0 , 7 9 0}$ & $\mathbf{- 0 , 8 0 5}$ \\
\hline $\begin{array}{c}\text { Rainfall } \\
\text { duration t, } \\
\text { min }\end{array}$ & 0,751 & 0,015 & 1,000 & 0,208 & 0,432 & 0,362 \\
\hline $\begin{array}{c}\text { Correlation } \\
\text { coefficient R, } \\
\text { test dataset }\end{array}$ & 0,048 & $-0,034$ & 0,208 & 1,000 & $-0,183$ & 0,090 \\
\hline MSE, dm ${ }^{3} / \mathrm{s}$ & $\mathbf{0 , 9 0 1}$ & $\mathbf{0 , 7 9 0}$ & 0,432 & $-0,183$ & 1,000 & $-0,623$ \\
\hline MPE, \% & $-0,326$ & $\mathbf{- 0 , 8 0 5}$ & 0,362 & 0,090 & $-0,623$ & 1,000 \\
\hline
\end{tabular}

\section{Conclusions}

The efficiency of the functioning of combined sewer systems is influenced by the random nature of water consumption (and, as a consequence, of wastewater discharge) as well as by the hardly predictable nature of rainfall and additional operational factors, such as the influence of the operations of the pumping stations. Due to these variables, predicting the state and efficiency of the sewer system is a multi-criterial issue that is difficult to describe with the use of simple correlations. The results of the analysis of the operational efficiency of two combined sewer pipes, circular and horseshoe-shaped, during five selected rainfall events and two dry weather periods demonstrate that the algorithms of Artificial Neural Networks (ANNs) and, more specifically, a one-directional, multi-layered, MLP (MultiLayered Perceptron) type network may be implemented to predict the flow rates based on the data concerning the wastewater depth in sewers. The analysis demonstrated a statistically significant correlation between the obtained flow rates in sewer pipes and rainfall depth and duration. The models obtained with the use of ANNs show a good and very good accuracy of predictions for heavy rainfall with a short and long duration (MPE ranging from -4.67 to $1.85 \%$ ). Less accurate predictions were obtained for the model of wastewater flow in sewer pipes during torrential rain with a long duration. The MPE for circular and horseshoe-shaped sewers was $-5.52 \%$ and $-5.96 \%$, respectively. For all the created ANN models the coefficients of correlation of test datasets were not lower than 0.967 . 
Predicting the non-linear nature of wastewater flow in sewer systems has high potential, combined with saving time devoted to calculations in comparison to traditional, complex mathematical models. Another advantage is the potential possibility of limiting the costs of performing continuous measurements in sewer systems. The above benefits are a strong argument for the use of Artificial Neural Networks to predict the flow of wastewater in combined sewer systems. However, the application of ANNs does not mean completely neglecting the existing mathematical models or the numerical models that are increasingly commonly used for hydrodynamic simulations. Nowadays, numerical models should be used as the first step of verification and identifying the key points where potential operational problems may occur (e.g. flooding or an increased number of failures). In the next stage, these points should be marked as the locations for conducting measurement campaigns. Further on, the historical data from such campaigns should be used in the learning process of Artificial Neural Networks. The presented method of predicting the flow rates in sewers may be used by sewer system administrators in the daily operations of sewer networks, for example to recognize the hydraulic conditions that occur in varied operational states of the system, to assess the reliability of sewer facilities, to improve the efficiency of controlling the system during extreme rainfall events and to assess the influence of stormwater flows on the receiving water bodies.

\section{References}

1. Y. Abou Rjeily, O. Abbas, M. Sadek, I. Shahrour, F. Hage Chehade, Water Sci. Technol. 77, 2401 (2017)

2. M.A. Aziz, M.A. Imteaz, T.A. Choudhury, D.I. Phillips, 19th International Congress on Modelling and Simulation, (Modelling and Simulation Society of Australia and New Zealand, Perth, 2011)

3. A. Służalec, Studia i Materiały Informatyki Stosowanej 4, 17 (2012)

4. D. Graupe, Principles of Artificial Neural Networks (World Scientific, 2013)

5. S.H. Elsafi, AEJ 53, 655 (2014)

6. L.H. Feng, J. Lu, Expert Syst Appl 37, 2974 (2010)

7. P.T. Nastos, K.P. Moustris, I.K. Larissi, A.G. Paliatsos, Atmospheric Res. 119, 153 (2013)

8. S. Kim, Y. Matsumi, S. Pan, H. Mase, Ocean Eng. 122, 44 (2016)

9. D.H. Lee, D.S. Kang, Procedia Eng 154, 1217 (2016)

10. P. Licznar, J. Łomotowski, Ochrona Środowiska 28, 45 (2006)

11. R. Jeż, Studia Ekonomiczne. Zeszyty Naukowe Uniwersytetu Ekonomicznego w Katowicach 217, 182 (2015)

12. E. Coppola jr., M. Poulton, E. Charles, J. Dustman, F. Szidarovszky, Nat Resour Res 12, 379 (2003)

13. A.P. Duncan, A. S. Chen, E.C. Keedwell, S. Djordjević, D.A. Savić, Weather Radar and Hydrology (IAHS-AISH Publication, Exeter, 2012)

14. S. Mounce, W. Shepherd, G. Sailor, J. Shucksmith, A.J. Saul, Water Sci. Technol. 69, 1326 (2014)

15. B. Kaźmierczak, A. Kotowski, Theor. Appl. Climatol 118, 285 (2014)

16. M. Rogalska, Z. Hajducki, Zeszyty Naukowe, Wyższa Szkoła Oficerska Wojsk Lądowych im. gen. T. Kościuszki 2, 285 (2011) 